\title{
A SYNTHETICAL STUDY OF THE IDENTIFICATION OF TEA-LEAVES GRADES OF QUALITY WITH SENSE ORGANS
}

\author{
Luo Yongtai \\ (Tianjin Urban Construction Institute) \\ Liu Naishen \\ (The Second Commercial Bureat of Tianjin) \\ Zhao Zhanyi \\ (Tianjin Jeyuan Waterworks)
}

\begin{abstract}
It has been a long time since the traditional process came into use for the identification of tea-leaves grades of quality with sense organs in China. However. there are a lot of changeable factors and wider subjective errors, so the identification accuracy has been unsatisfactory. This paper presents a new practical and systematic process, which is formed with the Analytic Hierarchy Process (AHP) and the Fuzzy Synthetical Evaluation Process. The tea-leaves grades of quality identified with this new process are objective and reliable. It is also suitable for the identification of food with sense organs.
\end{abstract}

\section{PROBLEMS}

Now in China, for the identification of tea-leaves grades of quality. the examination with sense organs is the main traditional process, in which the judges compare the tea-leaves' appearance. fragrancy. flavour, colour of tea-water, and swelled-up tea-leaves with those of the sample, give their corresponding evaluations, then sum up their opinions on each aspect and finally determine the tea-leaves grades and subdivided grades. However, there are no clear unified standards for the criteria. And the existing ones are too sweeping. Moreover. the judges may hold different biases and views. Therefore, the results differ between the judges greatly. In addition. there is a deviation of the. judgement from the real quality. In view of the above-mentioned facts, a new practical and systematic process of identification is presented in this paper. AHP is first adopted in the new process, in which the hierarchical structure of judgement is set up, and the priorities of the subdivided criteria are rationally determined, and the various results of judgement are synthesized by the Fuzzy Synthetical Identification Process.

II. The Set-up of the Hierarchical Structure and the Determination of the priorities of the Various Criteria by AHP

1. The Hierarchical Structure of the Criteria of Tea-leaves Grades of Quality

On the basis of the Standards GH 016-84 issued by The State Commerce Department of the P.R.C. and the rich experience gained through years of judging tea-leaves by the judges and technicians, the criteria of tea-leaves grades of quality can be divided into four levels.

Level $A$ is the goal level of Tea-leaves Grades of Quality.

Level B is the requirement level of Appearance (B1) and Inner Quality (B2). 
For D8 and D9 in Colour of Tea-water (C3). the matrix of peirwise comparisons is where $\mathrm{i}=8,9 \quad \mathrm{HC}-\mathrm{DH}=\left(\begin{array}{cc}1 & 0.45 \\ 1 / 0.45 & 1\end{array}\right)$

For D10, D11 and D12 in Swelled-up Tea-leaves (C4). the matrix of pairwisa comparisons is

where $i=10,11,12$

$$
\mathrm{HCA}-\mathrm{Di}=\left|\begin{array}{ccc}
1 & 2.4 & 4 \\
1 / 2.4 & 1 & 1.7 \\
1 / 4 & 1 / 1.7 & 1
\end{array}\right|
$$

According to Power Method. the maximal eigenvalue ( $\lambda$ max) and the corresponding priorities of the various matrixes of pairwise comparisons can be extracted. *

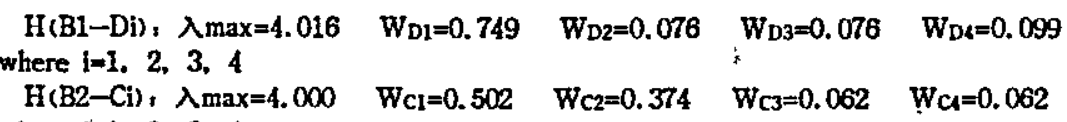

where $\hat{f}=1.2,3,4$

$H(C 2-D i): \lambda \max =2.000 \quad W_{D 6}=0.667^{\circ} W_{D}=0.333^{\circ}$

where $i=6,7$

$H(C 3-D i): \hat{\lambda}_{\max }=2.000$. WDB $=0.310 \quad W_{D g}=0.690$

where $i=8,9$;

$\mathrm{H}(\mathrm{C} 4-\mathrm{Di}): \lambda \max =3.000 \quad W_{D 10}=0.600 \quad W_{D 11}=0.251 \quad W_{D 12}=0.149$

where $\mathrm{i}=10,11,12$

The consistency of each of the matrixes of pairwise comparisons with the totality has been verified. so the priorities of the criteria in each level can be calculated, shown in Table 2.

\begin{tabular}{c|c|c}
\multicolumn{3}{|c}{ Table 2 } \\
\hline Leve & Crterion & \multicolumn{1}{c}{ Priority } \\
\hline B & B1 & 0.200 \\
C & B2 & 0.800 \\
& & $0.800 \times 0.502=0.401$ \\
& C4 & $0.800 \times 0.374=0.299$ \\
& & $0.800 \times 0.062=0.050$ \\
& D1 & $0.800 \times 0.062=0.050$ \\
\hline & D2 & $0.200 \times 0.749=0.150$ \\
D & D3 & $0.200 \times 0.076=0.015$ \\
& D4 & $0.200 \times 0.076=0.015$ \\
& D5 & $0.200 \times 0.099=0.020$ \\
& D6 & \\
& D7 & $0.299 \times 0.667=0.199$ \\
& D8 & $0.299 \times 0.333=0.100$ \\
& D9 & $0.050 \times 0.310=0.016$ \\
& D10 & $0.050 \times 0.690=0.034$ \\
& D11 & $0.050 \times 0.600=0.030$ \\
& D12 & $0.050 \times 0.251=0.013$ \\
& & $0.050 \times 0.149=0.007$ \\
\hline
\end{tabular}

3. The Determination of the Judgement Standards for Each Criterion

Following the determination of the priority of each subdivided criterion. the standards of giving marks are to be determined for the subdivided grades of each criterion with several stipulations concerned. The standards are shown in Table 3. 
Level $\mathrm{C}$ is the subrequirement level, in which Inner Quality (B2) is subdivided into Fragrancy (CI), Flavour (C2). Colour of Tea-water (C3) and Swelled-up Tea-leaves (CA)

- Level $D$ is the criterion level. in which Appearance (BI) is subdivided into Strip of Cord (D1), Colour \& Lustre (D2), Intactness \& Oddment (D3) and Pureness \& Cleanness (D4),Fragrancy in Level $C$ is directly used as a criterion (D5) in the lowest level, Flavour in Level $\mathrm{C}$ is subdivided into Delicacy \& Tenderness (D6) and Strength (D7): Colour of Tea-water in Level C into Colour \& Lustre (D8) and Transparency (D9). Swelled-up Tea-leaves in Level C into Tenderness. (D10). Evenness (D11), and Colour \& Lustre (D12).

The hierarchical structure of the criteria is shown in Table 1. These criteria are convenient to determine the specific standards of judgement and decrease the errors of sense organs in judgement.

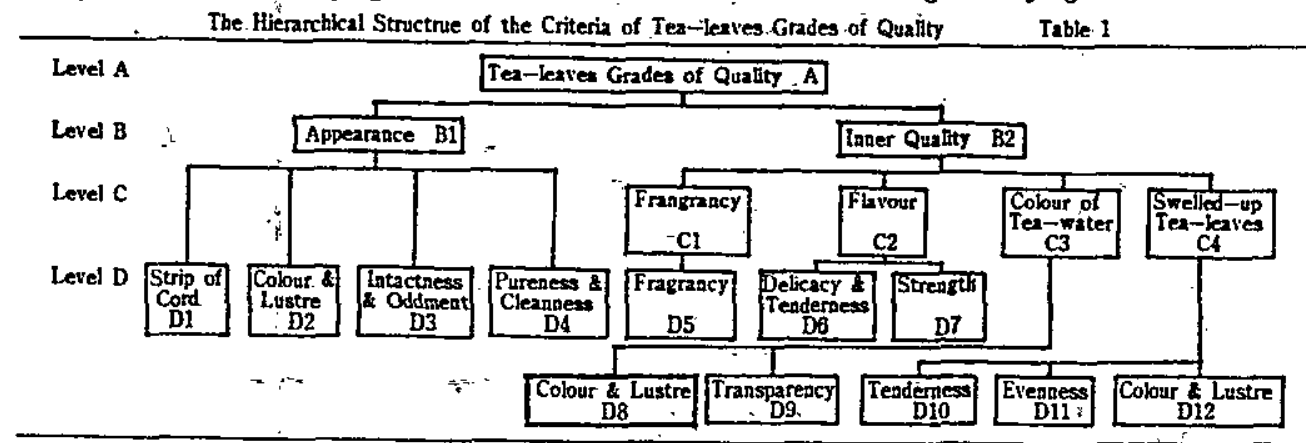

2. The Determination of the Priority of Each Criterion

On the basis of the Standards issued by The State Commerce Department of the P. R.C.. in Level B. the ratio between the importance of Appearance (B1) and that of Inner Quality (B2) is 1,4. so the priority of $\mathrm{BI}$ is 0.20 , or $\mathrm{W}_{\mathrm{BI}}=0.20$, the priority of $\overline{\mathrm{B} 2}$ is 0.80 . or $\mathrm{W}_{\mathrm{B} 2}=0.80$.

In accordance with the principle of the scaie of AHP, the experts concerned, who are engaged, get the following matrixes of pairwise comparisons between the criteria in Level $C$ and Level $D$.

For D1, D2, D3 and D4 in Appearance (B1), the matrix of pairwise comparisons is

where $i=1,2,3,4$

$$
H_{B 1-D 1}=\left(\begin{array}{cccc}
1 & 9 & 9 & 9 \\
1 / 9 & 1 & 1 & 7 / 10 \\
1 / 9 & 1 & 1 & 7 / 10 \\
1 / 9 & 10 / 7 & 10 / 7 & 1
\end{array}\right)
$$

For $\mathrm{C} 1, \mathrm{C} 2 . \mathrm{C} 3$ and $\mathrm{C} 4$ in Inner Quality (B2), the matrix of pairwise comparisons is

where $i=1,2,3,4$

$$
\mathrm{HBz}-\mathrm{Ci}=\left(\begin{array}{cccc}
1 & 1.344 & 8 & 8 \\
1 / 1.35 & 1 & 6 & 6 \\
1 / 8 & 1 / 6 & 1 & 1 \\
1 / 8 & 1 / 6 & 1 & 1
\end{array}\right)
$$

For D6 and D7 in Flavour (C2), the matrix of pairwise comparisons is

where $i=6,7 \quad \mathrm{HC} 2-\mathrm{D} i=\left(\begin{array}{cc}1 & 2 \\ 1 / 2 & 1\end{array}\right)$ 
In addition to the above-mentioried criteria. peculiar smeils should be considered as a specific criterion. If the tea-leaves have no pecullar smell, the total will not be affected. If the tea-leaves have a peculiar smell, the specific criterion can be dealt with in the two following cases.

Table 3

\begin{tabular}{|c|c|c|}
\hline Criterion & Degree & Score \\
\hline $\begin{array}{l}\text { Strip of Cord } \\
\text { DI }\end{array}$ & 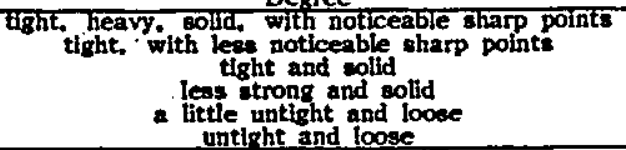 & $\begin{array}{r}100 \\
94 \\
75 \\
63 \\
50 \\
31\end{array}$ \\
\hline Colour $\frac{8}{\mathrm{D} 2}$ Lustre & $\begin{array}{c}\text { gess green and oleek } \\
\text { green and a little sleek } \\
\text { yellow and green } \\
\text { green and yollow } \\
\text { green and yellow with a little loose }\end{array}$ & $\begin{array}{r}100 \\
84 \\
67 \\
50 \\
34 \\
17 \\
\end{array}$ \\
\hline $\begin{array}{l}\text { Intactnes: } \\
\text { Oddment } \\
\text { D3 }\end{array}$ & $\begin{array}{c}\text { even and regular } \\
\text { even and complete } \\
\text { lese even and complete } \\
\text { complete } \\
\text { less complete }\end{array}$ & $\begin{array}{r}100 \\
67 \\
50 \\
34 \\
17\end{array}$ \\
\hline $\begin{array}{l}\text { Pureness } \\
\text { Cleanness } \\
\text { D4 }\end{array}$ & $\begin{array}{l}\text { with a few tender veins } \\
\text { with some tender veins } \\
\text { with veins and leaflets } \\
\text { with more leaflets } \\
\text { with leaflets and thick veins }\end{array}$ & $\begin{array}{r}100 \\
90 \\
80 \\
70 \\
50 \\
40\end{array}$ \\
\hline $\begin{array}{l}\text { Fragrancy } \\
\text { D5 }\end{array}$ & $\begin{array}{l}\text { fresh and strong } \\
\text { less fresh } \\
\text { ocent and mellow } \\
\text { weak }\end{array}$ & $\begin{array}{r}100 \\
95 \\
90 \\
80\end{array}$ \\
\hline $\begin{array}{c}\text { Delicacy \& } \\
\text { Tenderness } \\
\text { DB }\end{array}$ & $\begin{array}{l}\text { tender, scented and delicious, lasting } \\
\text { less tender and scented } \\
\text { much less tender and scented } \\
\text { pure } \\
\text { less pure } \\
\text { less plain } \\
\text { plain }\end{array}$ & $\begin{array}{r}100 \\
98 \\
95 \\
90 \\
88 \\
80 \\
70\end{array}$ \\
\hline $\begin{array}{l}\text { Strength } \\
\text { DF }\end{array}$ & $\begin{array}{l}\text { fresh and delicious } \\
\text { fresh and mellow } \\
\text { mellow } \\
\text { mellow and gentle } \\
\text { gentie } \\
\text { plain and weak }\end{array}$ & $\begin{array}{r}100 \\
98 \\
97 \\
90 \\
80 \\
70\end{array}$ \\
\hline $\begin{array}{l}\text { Colour \& } \\
\text { Lustre } \\
\text { D8 }\end{array}$ & $\begin{array}{l}\text { bright yellow } \\
\text { dark yellow } \\
\text { green and yellow } \\
\text { dark }\end{array}$ & $\begin{array}{r}100 \\
80 \\
70 \\
60\end{array}$ \\
\hline $\begin{array}{c}\text { Transparency } \\
\text { D9 }\end{array}$ & $\begin{array}{l}\text { limpid } \\
\text { less limpid } \\
\text { bright } \\
\text { less bright } \\
\text { turbid }\end{array}$ & $\begin{array}{r}100 \\
90 \\
80 \\
70 \\
50\end{array}$ \\
\hline $\begin{array}{l}\text { Tenderness } \\
\text { D10 }\end{array}$ & $\begin{array}{c}\text { tender } \\
\text { less tender } \\
\text { pliable and tough } \\
\text { thick and overgrown }\end{array}$ & $\begin{array}{r}100 \\
90 \\
85 \\
60\end{array}$ \\
\hline $\begin{array}{l}\text { Evenness } \\
\text { D11 }\end{array}$ & $\begin{array}{l}\text { most even } \\
\text { more even } \\
\text { even } \\
\text { less even } \\
\text { least even }\end{array}$ & $\begin{array}{r}100 \\
90 \\
80 \\
70 \\
6\end{array}$ \\
\hline $\begin{array}{l}\text { Colour it } \\
\text { Lutstre } \\
\text { D12 }\end{array}$ & $\begin{array}{l}\text { solt green } \\
\text { yellow green } \\
\text { dark green }\end{array}$ & $\begin{array}{r}100 \\
90 \\
80\end{array}$ \\
\hline
\end{tabular}

a) No Value of Drinking

For instance, if there is a camphor ball smell or other serious pollution of waste gases in the tea-leaves. one cannot drink them. They are harmful to one's health. Selling of such tea-leaves is not permitted and judgement is not needed either. 
b) With Light Peculiar Smelis, but Still Drinkable

For such tea-leaves, the total will be reduced according to the various degrees in Table 4.

\begin{tabular}{|c|c|}
\hline Dgree & Score \\
\hline $\begin{array}{c}\text { a smell of smoke } \\
\text { a light smell of smoke } \\
\text { a burnt smell } \\
\text { a light burnt smell } \\
\text { other peculiar smells }\end{array}$ & $\begin{array}{l}-21 \\
-19 \\
-17 \\
-14 \\
-12 \\
\end{array}$ \\
\hline
\end{tabular}

The model of the hierarchical structure of the identification of tea-leaves quality can be adjusted on the basis of the actual conditions in different areas. In judgement, for each item of criterion, the vivalue of the priority and the standards of giving marks can also be adjusted, in order to grade the same fumigated tea-leaves into different grades in the said area according to certain marks. Moreover. the subdivided grades of the same grade can be graded according to certain scores.

\section{AN EXAMPLE}

Tianjin laid in a stock of tea-lëaves of Grade II from Fujiza. In dry state, it looks good in appearance. The strips of cord are tight, heavy, solid and with noticeable sharp points. The colour is green and sleek. The appearance is tight, thin, even and regular. In wet checking, the sweel scent is mellow. The flavour is tender, scented and delicious, lasting, without any peculiar smell. The colour of tea-water is green and yellow, less bright. The swelled-up tea-leaves are less even , soft and tender. The colour of swelled-up tea-leaves is green and yellow. Try to determine its grade.

Making a check against the above-mentioned standards of giving marks, the given scores and total are shown in Table 5.

Table 5

\begin{tabular}{c|c|c|c}
\hline Criterion & Priority & Score & Priority $\times$ Score \\
\hline D1 & 0.150 & 100 & 15.00 \\
D2 & 0.015 & 100 & 1.50 \\
D3 & 0.015 & 100 & 1.50 \\
D4 & 0.020 & 100 & 2.00 \\
D5 & 0.401 & 90 & 36.09 \\
D6 & 0.199 & 100 & 19.90 \\
D7 & 0.100 & 100 & 10.00 \\
D8 & 0.016 & 70 & 1.12 \\
D9 & 0.034 & 85 & 2.38 \\
D10 & 0.030 & 80 & 1.55 \\
D11 & 0.013 & 90 & 0.07 \\
\hline D12 & 0.007 & & 93.75 \\
\hline Total & 1.000 & & \\
\hline
\end{tabular}

Conclusion: The stock of tea-leaves belongs to the medium subdivided grade in Grade II.

\section{The Fuzzy Synthetical Evaluation}

There are two approaches to synthetically evaluate the various results of the judges by means of Fuzzy Theory.

\section{The Composite Algorithm with Fuzzy Matrixes}

Let it be supposed that the set of the evaluation factors is 
$U=(u(1), u(2), \ldots, u(m))$

its corresponding priority is

$A=(a(1), a(2), \ldots, a(m))$

Assuming that the set of the evaluation criteria is

$V=(v(1), v(2), \ldots, v(s))$

its corresponding evaluation matrix is

$$
R=\left(\begin{array}{cccc}
r(11) & r(12) & \ldots & r(1 s) \\
r(21) & r(22) & \ldots & r(2 s) \\
\ldots & \ldots & \\
r(m 1) & r(m 2) & \ldots & r(m s)
\end{array} \mid\right.
$$

When considering the synthetical evaluation of The Stressed Main Factor Type (Wang Guangyuan. 1984), the Composite Algorithm with Fuzzy. Matrixes may be adopted, that is

where

$$
\begin{aligned}
C=A & =R=(a(1), a(2), \ldots a(m)) \cdot \cdot\left[\begin{array}{cccc}
r(11) & r(12) & \ldots & r(1 s) \\
r(21) & r(22) & \ldots & r(2 s) \\
\ldots & & \ldots \\
r(m 1) & r(m 2) & \ldots & r(m s)
\end{array}\right) \\
& =(C(j)) 1 \times s
\end{aligned}
$$

$$
\begin{aligned}
C(j) & =\max \min (a(k), r(k j)) \\
& =V(a(k) \wedge r(k j))
\end{aligned}
$$

According to the principle of the maximal degree of membership,

when $\quad C(i)=\max \{c(1), c(2), \cdots, c(m)\}$

the evaluation result is $V(i)$.

\section{AN EXAMPLE}

Let it be supposed that the evaluation field of jasmine tea-leaves is $U$.

$$
\begin{aligned}
U= & \{\text { Appearance }(u(1)) . \text { Fragrancy (u(2)). Flavour (u(3)), } \\
& \text { Colour of Tea-water (u(4). Swelled-up Tea-leaves }(u(5) ;\}
\end{aligned}
$$

Assuming that the priority is

$$
A=(0.2,0.4,0.3,0.05,0.05)
$$

and the set of evaluation criteria is

$$
\begin{aligned}
v= & \text { (Deg.I }(v(1)) \text {. Deg. II }(V(2)) \text {. Deg. III }(v(3)) \\
& \text { Deg. IV \{v(4)). Deg. } V\{v(5))\}
\end{aligned}
$$

In our own organization, the score intervals of the degrees are shown in Table 6 . Table 6

\begin{tabular}{c|c}
\hline Degree & Score \\
\hline II & $91-100$ \\
III & $81-90$ \\
IV & $71-80$ \\
V & $61-70$ \\
\hline
\end{tabular}


There are ten judges giving the scores for the various criteria, shown in Table 7. (unit: person) Table 7

\begin{tabular}{|c|c|c|c|c|c|}
\hline Crierion & -5 & $m$ & Degtee & & \\
\hline & 1 & 11 & III & IV & $\mathrm{V}$ \\
\hline $\begin{array}{l}\text { Appearance } \\
\text { Fragrancy } \\
\text { Flavour } \\
\text { Colour of Tea-water } \\
\text { Swelled } \rightarrow \text { up Tea-leaves }\end{array}$ & $\begin{array}{l}0 \\
0 \\
0 \\
0 \\
0\end{array}$ & $\begin{array}{l}1 \\
2 \\
1 \\
0 \\
0\end{array}$ & $\begin{array}{l}4 \\
4 \\
5 \\
4 \\
5\end{array}$ & $\begin{array}{l}3 \\
2 \\
4 \\
4 \\
4\end{array}$ & $\begin{array}{l}7 \\
2 \\
0 \\
2\end{array}$ \\
\hline
\end{tabular}

Dividing each value in Table 7 by 10 (the total of the judges), the evaluation matrix is

therefore

$$
R=\left(\begin{array}{ccccc}
0 & 0.1 & 0.4 & 0.3 & 0.2 \\
0 & 0.2 & 0.4 & 0.2 & 0.2 \\
0 & 0.1 & 0.5 & 0.4 & 0 \\
0 & 0 & 0.4 & 0.4 & 0.2 \\
0 & 0 & 0.5 & 0.4 & 0.1
\end{array}\right)
$$

further, owing to

$$
\begin{aligned}
C & =A \cdot R=\left(\begin{array}{lll}
0.2, & 0.4, & 0.3,0.05,0.05
\end{array}\right) \cdot\left(\begin{array}{ccccc}
0 & 0.1 & 0.4 & 0.3 & 0.2 \\
0 & 0.2 & 0.4 & 0.2 & 0.2 \\
0 & 0.1 & 0.5 & 0.4 & 0 \\
0 & 0 & 0.4 & 0.4 & 0.2 \\
0 & 0 & 0.5 & 0.4 & 0.1
\end{array}\right) \\
& =\left(\begin{array}{lll}
0, & 0.2,0.4,0.3,0.2
\end{array}\right)
\end{aligned}
$$

$$
\max \{0,0.2,0.4,0.3,0.2\}=0.4 \text {. }
$$

Conclusion. This stock of Jasmine tea-leaves belongs to Degree III, that is. $v(3)$ (Score 71 -80). It should be deserved extra attention that this alogrithm must presuppose that it doesn' $t$ lose effectiveness. -The discussion on the algoritim is without going into detail.

\section{The Algorithm of Common Matrix Multiplication}

When considering the Joint effects of the various factors. with adopting The Weighted Average Type. The Algorithm of Common Matrix Multiplication may be used, that is

$$
\begin{aligned}
C=A: R & =(a(1), a(2), \cdots, a(m)) \cdot\left(\begin{array}{cccc}
r(11) & r(12) & \ldots & r(1 s) \\
r(21) & r(22) & \ldots & r(2 s) \\
\ldots & & \ldots \\
r(m 1) & r(m 2) & \ldots & r(m s)
\end{array}\right) \\
& =(C(j))_{1 \times s}
\end{aligned}
$$

where

$$
(C(j))=\sum_{k=1}^{m} a(k) \wedge r(k j)
$$

\section{AN EXAMPLE}

There are five fudges, whose authoritativenesses differ. The priorities of their authoritativenesses are $B=(0.3,0.2,0.2,0.15,0.15)$

The priorities of the five criteria of the stock of tea-leaves are the same as those in the above example:

$$
A=(0.2,0.4,0.3,0.05,0.05)
$$


In Table 8 are the scores given by each judge for the criteria.

Table 8

\begin{tabular}{c|c|c|c|c|c}
\hline \multirow{2}{*}{ Judge } & Appearance & Fragrancy & Chlavour & Colour of & Swe!led-up \\
\cline { 2 - 6 } & & & Tea-water & Tea-leaves \\
\hline 1 & 83 & 90 & 85 & 85 & 89 \\
2 & 92 & 88 & 83 & 96 & 90 \\
3 & 87 & 80 & 84 & 90 & 78 \\
4 & 71 & 82 & 77 & 80 & 86 \\
5 & 86 & 81 & 84 & 74 & 72 \\
\hline
\end{tabular}

Try to determine its grade.

In the light of the meaning of the example, we have

$$
\begin{aligned}
\mathrm{C} & =\mathrm{B} \cdot \mathrm{R}=(0.3,0.2,0.2,0.15,0.15) \cdot\left(\begin{array}{ccccc}
83 & 90 & 85 & 85 & 81 \\
92 & 88 & 83 & 96 & 90 \\
87 & 80 & 84 & 90 & 78 \\
71 & 82 & 77 & 80 & 86 \\
86 & 81 & 84 & 74 & 72
\end{array}\right) \\
& =(84,25,85.05,83.05,85.80,82.50)
\end{aligned}
$$

$$
\begin{aligned}
& =(84,25,85.05,83.05,85.80,82.50) / 84.25 \\
& A \cdot C^{\mathrm{I}}=\left(\begin{array}{lllll}
0.2, & 0.4, & 0.3, & 0.05,0.05
\end{array}\right) \cdot\left(\begin{array}{l}
85.05 \\
83.05 \\
85.80 \\
82.50
\end{array}\right)
\end{aligned}
$$

Conclustion: The stock of tea-leaves belongs to Grade II.

Both the priorities of the judges authoritativenesses and those of the various criteria are considered in this approach. Therefore. the result tallies with the actual situations better.

\section{SUMMARY}

1 The systematic process for the identification of tea-leaves presented in this paper can be convenienlly developed into special soft wase, with which the evaluation by man-machine interaction will become a reality.

2. Each area should set up the standards of the criteria for the identification of tea-leaves, and those of the division of grades and subdivided grades.

3. The process presented in this paper can be used for the similar identification of food with sense organs and for other similar synthetical evaluations.

\section{REFERENCES}

Thomas L. Saaty, "The Analytic Hierarchy Process". McGraw-IIII Inc. New York, 1980 Wang Guangyuan. "On the Essence of a Few Mathematical Modeis for Synthetical Evaluation". Fuzzy Mathematics, Volume 4, 1984

Waing Peizhuang. "Fuzzy Set Theory and its Applications". Shanghai Science and Technology Publishing House, 1984

Zhao Huanchen, Xu Shubo, He Jinsheng. “AHP-A New Simple and Easy Process of Police-Making ${ }^{\star}$. Science Publishing House, Spetember. 1986 